\title{
Respiratory manifestations of panic disorder: causes, consequences and therapeutic implications****
}

\author{
Manifestações respiratórias do transtorno de pânico: \\ causas, consequências e implicações terapêuticas \\ Aline Sardinha, Rafael Christophe da Rocha Freire, \\ Walter Araújo Zin, Antonio Egidio Nardi
}

\begin{abstract}
Multiple respiratory abnormalities can be found in anxiety disorders, especially in panic disorder (PD). Individuals with PD experience unexpected panic attacks, characterized by anxiety and fear, resulting in a number of autonomic and respiratory symptoms. Respiratory stimulation is a common event during panic attacks. The respiratory abnormality most often reported in PD patients is increased $\mathrm{CO}_{2}$ sensitivity, which has given rise to the hypothesis of fundamental abnormalities in the physiological mechanisms that control breathing in PD. There is evidence that PD patients with dominant respiratory symptoms are more sensitive to respiratory tests than are those who do not manifest such symptoms, and that the former group constitutes a distinct subtype. Patients with PD tend to hyperventilate and to panic in response to respiratory stimulants such as $\mathrm{CO}_{2}$, triggering the activation of a hypersensitive fear network. Although respiratory physiology seems to remain normal in these subjects, recent evidence supports the idea that they present subclinical abnormalities in respiration and in other functions related to body homeostasis. The fear network, composed of the hippocampus, the medial prefrontal cortex, the amygdala and its brain stem projections, might be oversensitive in PD patients. This theory might explain why medication and cognitive-behavioral therapy are both clearly effective. Our aim was to review the relationship between respiration and PD, addressing the respiratory subtype of PD and the hyperventilation syndrome, with a focus on respiratory challenge tests, as well as on the current mechanistic concepts and the pharmacological implications of this relationship.
\end{abstract}

Keywords: Panic disorder; Anxiety; Respiration; Hyperventilation; Carbon dioxide.

\section{Resumo}

Múltiplas anormalidades respiratórias podem ser encontradas em pacientes com transtornos de ansiedade, particularmente no transtorno de pânico (TP). Indivíduos com TP experimentam ataques de pânico inesperados, caracterizados por ansiedade, medo e diversos sintomas autonômicos e respiratórios. A estimulação respiratória é um fenômeno comum durante os ataques de pânico. A anormalidade respiratória mais citada em pacientes com TP é a sensibilidade aumentada para o $\mathrm{CO}_{2}$, que originou a hipótese de uma disfunção fundamental nos mecanismos fisiológicos de controle da respiração no TP. Há evidências de que pacientes com TP com sintomas respiratórios predominantes são mais sensiveis a testes respiratórios do que aqueles sem a manifestação de tais sintomas, representando um subtipo distinto. Pacientes com TP tendem a hiperventilar e a reagir com pânico como resposta a estimulantes respiratórios como o $\mathrm{CO}_{2}$, gerando uma ativação de um circuito de medo hipersensível. Apesar de a fisiologia respiratória desses pacientes permanecer normal, algumas evidências recentes apontam a presença de disfunções subclínicas na respiração e em outras funções relacionadas à homeostase corporal. 0 circuito do medo, composto pelo hipocampo, córtex pré-frontal medial, amígdala e projeções do tronco cerebral, pode estar hipersensível em pacientes com TP. Essa teoria pode explicar porque os medicamentos e a terapia cognitivocomportamental são claramente eficazes. Nosso objetivo foi revisar a relação entre respiração e TP, especialmente o subtipo respiratório de TP e a síndrome da hiperventilação, focalizando os testes respiratórios, bem como as hipóteses mecanísticas e as implicações farmacológicas dessa relação.

Descritores: Transtorno de pânico; Ansiedade; Respiração; Hiperventilação; Dióxido de carbono.

* Study carried out in the Laboratory of Panic and Respiration at the Instituto de Psiquiatria da Universidade Federal do Rio de Janeiro (IPUB/UFRJ, Institute of Psychiatry of the Federal University of Rio de Janeiro) and at the Instituto Nacional de Ciência e Tecnologia (INCT, National Institute of Science and Technology) -Translational Medicine - Rio de Janeiro, Brazil.

Correspondence to: Aline Sardinha. Laboratório de Pânico e Respiração, Av. Venceslau Brás, 71 Fundos, CEP 22290-140, Urca, Rio de Janeiro, RJ, Brasil.

Tel 5521 9417-2708. E-mail: alinesardinhapsi@gmail.com

Financial support: This study received financial support from the Brazilian Conselho Nacional de Desenvolvimento Cientifico e Tecnológico (CNPq, National Council for Scientific and Technological Development) and the Fundação de Apoio à Pesquisa do Estado do Rio de Janeiro (FAPERJ, Foundation for the Support of Research in the State of Rio de Janeiro).

Submitted: 26 January 2009. Accepted, after review: 17 March 2009.

** A versão completa em português deste artigo está disponível em www.jornaldepneumologia.com.br 


\section{Introduction}

Respiration and its control mechanisms play a prominent role in generating abnormal anxiety, particularly panic disorder. ${ }^{(1)}$ A panic attack typically begins with a sudden, unexpected rise of terror, accompanied by a number of autonomic, especially cardiorespiratory symptoms. ${ }^{(2)}$ Panic disorder has long been the focus of research into the relationship between the respiratory system and anxiety disorders. ${ }^{(3)}$

The hyperventilation syndrome seen during panic attacks has been characterized as having a chronic and an acute form. ${ }^{(4)} \mathrm{ln}$ this conceptual model, it is thought that disturbed breathing causes bursts of hyperventilation and respiratory alkalosis, triggering various somatic signs and symptoms, such as dizziness, tremors and palpitations, which precipitate fear and anxiety. ${ }^{(3)}$ Klein ${ }^{(5)}$ proposed the existence of an evolved "false suffocation alarm" system that triggers spontaneous panic attacks when the brain erroneously signals a lack of useful air and activates maladaptive autonomic responses to suffocation. Sensitivity to $\mathrm{CO}_{2}$ might play a role in this hypersensitive suffocation detector, ${ }^{(5)}$ and various respiratory tests, such as carbon dioxide inhalation, ${ }^{(6)}$ hyperventilation ${ }^{(7)}$ and breathholding, ${ }^{\left({ }^{8}\right)}$ have been fruitful in generating hypotheses about panic disorder. ${ }^{(3,5)}$ Panic disorder patients exhibit behavioral and physiological abnormal responses to respiratory challenge tests that are very similar to those experienced during spontaneous panic attacks. ${ }^{(4)}$ This phenomenological characterization of panic attacks and the response of panic disorder patients to the respiratory tests led to the subtyping of such patients. Briggs et al.(9) identified a subgroup of panic disorder patients presenting prominent respiratory symptoms, characterized by a greater number of spontaneous panic attacks, a better response to antidepressants, greater sensitivity to $\mathrm{CO}_{2}$ challenge and greater overall severity of the disorder.

The objective of this review was to describe the close relationship between panic disorder and respiration, in order to provide scientific data to guide the decision-making process in daily clinical practice. We address panic disorder with prominent respiratory symptoms, as well as the results of respiratory challenge tests. Therapeutic implications and current mechanistic concepts for panic disorder are also discussed.

\section{Hyperventilation syndrome}

In hyperventilation syndrome, there are complex interactions among organic, respiratory, psychiatric and physiological disturbances.(10) Anxiety disorders, such as panic disorder, are associated with mild hyperventilation and other breathing pattern abnormalities. ${ }^{(11)}$ There is a bidirectional association between hyperventilation and anxiety, as evidenced by the fact that individuals with idiopathic hyperventilation have been shown to score higher on anxiety and depression scales than do control subjects. ${ }^{(12)}$ Hyperventilation can therefore be considered a cause, a correlate and a consequence of panic attacks. ${ }^{(1,11)}$

Acute hyperventilation can produce anesthesia, paresthesia, ataxia, tremor, tinnitus, cold extremities, palmar hyperhidrosis, giddiness, loss of consciousness, visual disturbances, headache and chest pain. ${ }^{(10)}$ There is therefore symptom overlap between panic disorder and hyperventilation syndrome, since panic attacks include most of these symptoms, together with others, such as breathlessness, feeling of choking, nausea, derealization (an alteration in the perception or experience of the external world that makes it seem strange or unreal), depersonalization (an alteration in the perception or experience that causes a feeling of detachment from the mental processes or the body), fear of dying and fear of losing control. ${ }^{(2)}$

The prevailing hypothesis to explain the symptom overlap between acute hyperventilation and panic disorder is that panic disorder patients suffer from chronic episodes of hyperventilation, in which they shift toward hypocapnic alkalosis as a consequence of stress-induced acute hyperventilation, generating panic attacks. There are three major experimental findings to support that idea. First, panic attacks and hyperventilation syndrome both feature dyspnea, palpitations, tremors, paresthesia and giddiness. Second, hyperventilation syndrome overlaps with panic disorder in approximately $40 \%$ of patients. $^{(12)}$ Finally, the acute hyperventilation challenge test, in which patients hyperventilate (30 breaths/min) for $4 \mathrm{~min}$, reproduces paniclike symptoms in a significant proportion of panic disorder patients. ${ }^{(7)}$

Stress-induced hyperventilation produces symptoms that are frequently misinterpreted as life-threatening by patients who are unaware 
of the consequences of overbreathing. ${ }^{(13)}$ Misinterpretation of these symptoms increases fear and activates the autonomic nervous system, thus increasing respiratory frequency, which causes further $\mathrm{CO}_{2}$ washout and intensifies the hypocapnic symptoms. ${ }^{(4)}$ This creates a positive feedback loop, increasing the panic response and giving rise to a panic attack.

One of the leading organic causes of hyperventilation syndrome is asthma. ${ }^{(10)}$ In one sample of asthma patients, 36\% were found to suffer from hyperventilation syndrome. ${ }^{(14)}$ In that study, the majority (78\%) of the asthma patients with hyperventilation syndrome were women. In addition, the patients with asthma and hyperventilation syndrome more often presented with basal dyspnea, were more sensitive to anxiety and more often sought emergency room treatment for exacerbations.

Asthma has also been correlated with panic disorder and other psychiatric comorbidities, independent of the degree of asthma severity. ${ }^{(15)}$ Asthma patients with panic disorder report illness-specific and generalized panic/fear more often than do those without panic disorder. Asthma patients reporting illness-specific panic/ fear also report poorer health-related quality of life, including emotional disturbance. 1llnessspecific panic/fear has been associated with more primary care office visits for asthma, greater irritability during asthma attacks, increased restriction of activities and greater use of rescue medication. ${ }^{(14)}$

It is possible that hypocapnia induced by hyperventilation creates symptoms that asthma patients cannot control by using asthma medication, and that their perceived control over the management of their disease is therefore impaired. ${ }^{(16)}$ Clinical anxiety and panic manifestations affect symptom perception and asthma management directly, due to the effects of anxiety symptoms such as hyperventilation, and indirectly, due to changes in self-management behavior and physician response. Therefore, behavioral interventions designed to improve quality of life and treatment response among such patients should be tested. ${ }^{(17)}$

\section{Underlying mechanisms of panic disorder}

\section{Increased $\mathrm{CO}_{2}$ sensitivity}

There are two lines of evidence suggesting that panic attacks originate in the brain stem. ${ }^{(3)}$ The first advances the idea that the nature of the symptoms can be explained by a

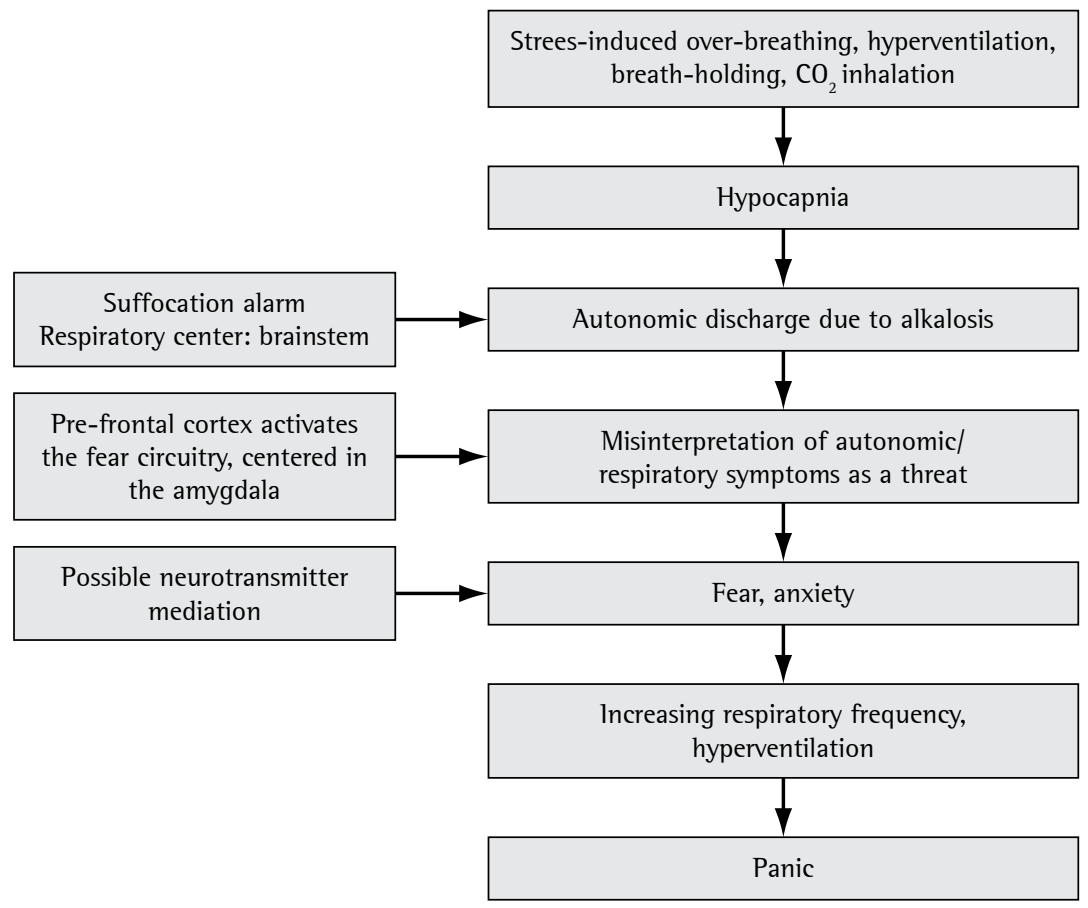

Figure 1 - Panic attack mechanisms. 
surge of impulses from the autonomic nervous system. The second line of evidence is related to the $\mathrm{CO}_{2}$-mediated experimental provocation of panic attack itself, since $\mathrm{CO}_{2}$ primarily affects the brain stem, especially the respiratory center, located in the reticular substance of the medulla oblongata and the pons. ${ }^{(3)}$

Klein $^{(5)}$ proposed that panic attack results from the dysregulation of a phylogenetically evolved alarm system directed at monitoring signals of suffocation. This alarm system has been evolutionarily programmed to be activated when there are metabolic signs of asphyxia and impending death. As a survival alert system, this suffocation monitor most likely serves a deeply rooted adaptive function, being activated only in extreme life-threatening circumstances. The Klein hypothesis might help us understand the preeminence of respiratory symptoms in panic attacks. One drawback of the hypothesis is that no "false suffocation alarm" system has been anatomically or functionally identified as such within the central nervous system. Attempts to identify the panic circuitry in the brain should focus on the chemosensitive areas of the central nervous system.

Considering the hyperoxic nature of the substances used in $\mathrm{CO}_{2}$ challenge, any stimulating influence of the peripheral oxygen chemosensitive areas can be ruled out. Studies evaluating increased ventilation after the inhalation of increasing concentrations of $\mathrm{CO}_{2}$-which would indicate dysfunction at the level of the chemosensitive areas of the central nervous system-have yielded contradictory results. ${ }^{(3)}$ This could be partly explained by a lack of control for confounding variables and by the well-known wide interindividual variability in $\mathrm{CO}_{2}$ sensitivity.
Although we understand that intermittent hypoxia can have a different effect in panic disorder patients than in healthy controls, we have yet to identify the specific mechanism by which panic disorder patients are exposed to this phenomenon. There is some evidence that chemosensitive areas of the central nervous system related to panic responses extend to several brain stem nuclei, including the nucleus tractus solitarius, the locus coeruleus and the raphe nuclei, all of which are within the broad brain stem respiratory network. ${ }^{(3)}$ These structures should logically be considered as the best candidates for the functional role of suffocation detector. In addition, panic disorder patients appear to lose a certain degree of effective homeostatic control after their physiological equilibrium has been disrupted by a respiratory stressor. ${ }^{(18)}$

\section{Genetic predisposition}

The influence of genetics on $\mathrm{CO}_{2}$-induced panic has also been studied. It has been suggested that $\mathrm{CO}_{2}$ sensitivity reflects a trait marker that runs in families. ${ }^{(19)}$ Hence, $\mathrm{CO}_{2}$ sensitivity can be considered a phenotypic expression of an underlying genetic predisposition that can exist before the clinical onset of panic disorder. ${ }^{(20)}$ The proposed genetic mechanisms include differential expression of chemoreceptors and its influence on neurotransmitter systems. The ultimate isolation of genetic markers could lead to preventive measures for vulnerable individuals. It remains unknown whether $\mathrm{CO}_{2}$ sensitivity and the resulting hyperventilation are characteristic of all normal subjects or only of panic disorder patients. It is possible that $\mathrm{CO}_{2}$ sensitivity is related to a specific subtype of panic disorder, is

Chart 1 - Practical applications of each respiratory test.

\begin{tabular}{|c|c|c|c|}
\hline $\begin{array}{c}\text { Respiratory } \\
\text { test }\end{array}$ & Procedure & $\begin{array}{l}\text { Diagnostic } \\
\text { accuracy }\end{array}$ & Symptoms \\
\hline Hyperventilation & 30 breaths/min for 4 min & ++ & $\begin{array}{l}\text { Panic attacks with predominant } \\
\text { respiratory symptoms in half of panic } \\
\text { disorder patients }\end{array}$ \\
\hline Breath-holding & $\begin{array}{l}\text { Three trials of cessation of breathing } \\
\text { after unforced exhalation, 2-min recovery } \\
\text { period. Fourth trial: breath-holding after } \\
\text { inhalation up to vital capacity }\end{array}$ & + & $\begin{array}{l}\text { Shorter breath-holding time in panic } \\
\text { disorder patients; lower end-tidal } \\
\qquad \mathrm{PaCO}_{2} \text { and anxiety }\end{array}$ \\
\hline $\mathrm{CO}_{2}$ inhalation & $\begin{array}{c}\text { A single inhalation up to vital capacity of } \\
\text { a gas mixture containing } 35 \% \mathrm{CO}_{2} \text { and } \\
65 \% \text { oxygen }\end{array}$ & +++ & $\begin{array}{c}\text { Neurovegetative panic-like symptoms } \\
\text { in normal subjects. Panic attacks in } \\
\text { most of panic disorder patients. }\end{array}$ \\
\hline
\end{tabular}


Chart 2 - Symptoms and clinical features of the respiratory panic disorder subtype.

\begin{tabular}{|lc|}
\hline & Respiratory panic disorders subtype \\
Sympytoms & Clinical caracteristics \\
More three of the following & More spontaneous panic attack \\
1. Fear of dying & Hypersensitivity to $\mathrm{CO}_{2}$ \\
2. Chest pain/discomfort & Panic attack during respiratory tests \\
3. Shortness of breath & Better response to antidepressants \\
4. Paresthesias & \\
5. Sensation of choking & \\
\hline
\end{tabular}

a hypersensitive homeostatic response (the "false suffocation alarm") or is simply an indirect cause of panic by means of nonspecific irritation of any number of chemical or mechanical receptors.

Many authors have found that healthy relatives of panic disorder patients are significantly more likely to react to $\mathrm{CO}_{2}$ challenge than are healthy subjects without a familial history of panic disorder. The authors of one study found that the rates of $\mathrm{CO}_{2}$-induced panic attacks suggested an association between hypersensitivity to $\mathrm{CO}_{2}$ and genetic predisposition to panic disorder. ${ }^{(21)}$ Those authors concluded that panic disorder patients and individuals genetically predisposed to panic disorder are at an increased risk for experiencing smothering symptoms. In that same study, the risk of developing panic disorder was found to be significantly higher for patients who were hypersensitive to $\mathrm{CO}_{2}$ than for subjects with normal reactivity to $\mathrm{CO}_{2}(14.4 \% \mathrm{vs}$. $3.9 \%$ ), suggesting that hypersensitivity to $\mathrm{CO}_{2}$ is associated with a subtype of panic disorder specifically related to greater genetic predisposition. ${ }^{(21)}$ In addition, the authors stated that $\mathrm{CO}_{2}$ challenge has predictive value, since relatives of panic disorder patients with respiratory symptoms presented an approximately threefold higher risk for panic and a nearly six-fold higher risk for panic with smothering symptoms in comparison with relatives of panic disorder patients without respiratory symptoms. ${ }^{(21)}$ Children of panic disorder patients also exhibit greater variability in numerous physiological respiratory parameters in comparison with the children of healthy individuals. ${ }^{(20)}$

Taken together, the results of these studies support the idea that the panic-respiration connection might foster a further step in the quest to identify a valid gold standard for use in determining panic disorder phenotype. Hypersensitivity to $\mathrm{CO}_{2}$ bears a relevant genetic component and seems to be significantly related to genetic predisposition to panic disorder. In addition, $\mathrm{CO}_{2}$ hypersensitivity might represent the phenotypical expression of genetic predisposition to panic disorder, even when clinically absent. Therefore, subjects with $\mathrm{CO}_{2}$ hypersensitivity or respiration abnormalities might be considered "affected" members in molecular genetic studies. Alternatively, hypersensitivity to $\mathrm{CO}_{2}$ could be considered the phenotypic expression of one of the genes involved in the respiratory panic disorder subtype. Therefore, the "true" phenotype for genetic studies could be defined solely by clinically expressed panic and $\mathrm{CO}_{2}$ hypersensitivity. If the etiology of panic disorder is strongly related to genetic factors and $\mathrm{CO}_{2}$ hypersensitivity is linked to the pathogenesis of panic disorder, it can be presumed that $\mathrm{CO}_{2}$ hypersensitivity is modulated by genetic influences. This hypothesis is supported by the results of a study of twins, ${ }^{(22)}$ in which the rate of $\mathrm{CO}_{2}$-induced panic attacks was found to be significantly higher in monozygotic twins than in dizygotic twins (55.6\% vs. 12.5\%).

\section{The central nervous system hypothesis}

It is possible that panic disorder is caused by dysfunctions in the serotoninergic, opioid and gamma-aminobutyric acid systems. Although far from being confirmed, the assumption that abnormalities in neurotransmitters found in panic disorder reflect altered brain function is based on the effectiveness of drugs that modulate neurotransmitters (e.g., serotonin) in the treatment of panic disorder. The serotoninergic system influences the behavior of many brain areas involved in the regulation of body functions, and serotonin receptors have been found in many organs other than the brain. There is considerable evidence linking the serotoninergic system to peripheral respiratory function. Serotonin transporters are expressed in human 
pulmonary membranes and are important in the maintenance of upper airway patency in obstructive sleep apnea. ${ }^{(23,24)}$ Sertraline, a selective serotonin reuptake inhibitor, reduces dyspnea in patients with COPD, ${ }^{(25)}$ and paroxetine relieves respiratory symptoms in patients with obstructive sleep apnea. ${ }^{(26)}$

The endogenous opioid system has been recognized as an important regulator of the central respiratory drive. ${ }^{(27)}$ When the opioid receptors are stimulated, $\mathrm{CO}_{2}$ sensitivity reduces and the respiratory rate slows. Conversely, the opioid receptor antagonist naloxone increases the ventilatory response to hypercapnic hypoxia in normal human subjects. ${ }^{(28)}$ Opioid deficiency could explain why lactate induces panic attacks. $^{(29)}$ To explore this hypothesis, one group of authors administered intravenous naloxone and sodium lactate to twelve normal controls. ${ }^{(28)}$ Although none of the subjects felt anxious, experienced fear or had a panic attack, they all presented with panic symptoms and increased tidal volume.

Recent studies analyzing the neurobiology of conditioned fear responses have employed a model of panic disorder that attempts to integrate neurochemical, neuroimaging and treatment findings with mostly preclinical data. ${ }^{(1,3,29)}$ Panic attacks are thought to originate from an abnormally sensitive fear network, centered in the central nucleus of the amygdala (CNA). The sensory input for the conditioned fear stimulus runs through the anterior thalamus to the lateral nucleus of the amygdala, thence to the CNA, where all the information is gathered and the autonomic and behavioral responses are coordinated. The CNA sends stimuli to the following structures: the parabrachial nucleus, increasing respiration rate; ${ }^{(29)}$ the lateral nucleus of the hypothalamus, activating the sympathetic nervous system; the locus coeruleus, increasing norepinephrine release, blood pressure, heart rate and the behavioral fear response; and the paraventricular nucleus of the hypothalamus, increasing the release of adrenocorticotropic hormone. A projection from the CNA to the periaqueductal gray region is responsible for additional behavioral responses, including defensive behaviors and postural freezing.

Although the amygdala receives direct sensory input from brain stem structures and the sensory thalamus, enabling a rapid response to potentially threatening stimuli, it also receives afferents from cortical regions involved in the processing and evaluation of sensory information. ${ }^{(3,30)}$ There are also important reciprocal connections between the amygdala and the sensory thalamus, prefrontal cortex, insula and primary somatosensory cortex. A neurocognitive deficit could result in a misinterpretation of sensory information, leading to inappropriate activation of the fear network via misguided excitatory input to the amygdala.

A deficiency in the coordination of the stimuli from the cortex and brain stem could lead to abnormal activation of the amygdala, with behavioral, autonomic and neuroendocrine stimulation. Panic originates from within an abnormally sensitive fear network, which includes the prefrontal cortex, insula, thalamus and amygdalae, as well as amygdalar projections to the brain stem and hypothalamus. ${ }^{(3,29)}$ Evidence supporting this idea has emerged from recent neuroimaging studies indicating that the amygdala, anterior cingulate cortex and insula play a crucial role in the pathophysiology of anxiety disorders. ${ }^{(30)}$

In addition to the evidence of strong connections between the amygdala and the carotid body, it has been suggested that the direct sensitivity of amygdale to acid-base changes, together with the interconnections between the amygdale and the parabrachial nucleus, ${ }^{(31)}$ constitute an alternative pathway linking respiratory signals to panic. ${ }^{(32)}$ The potential role of hypoxia as a marker of asphyxia, as well as the suggested sensitivity of panic disorder patients to anoxia, is supported by evidence from animal studies reporting that the amygdala and the hippocampus are particularly sensitive to anoxic stimulation. A summary of the panic attack process can be seen in Figure 1.

\section{Diagnostic challenge tests}

The various diagnostic challenge tests are compared in Chart 1.

\section{Hyperventilation}

The acute hyperventilation challenge test (30 breaths/min for $4 \mathrm{~min}$ ) can reproduce panic-like symptoms in a significant proportion of panic disorder patients. ${ }^{(33)} \mathrm{ln}$ a previous study, ${ }^{(7)}$ our group described the clinical features 
of hyperventilation-induced panic attacks in panic disorder patients and compared them with their spontaneous panic attacks, as well as with spontaneous panic attacks in panic disorder patients not sensitive to the hyperventilation challenge test. Of the 88 panic disorder patients evaluated, 45 (51.1\%) developed a panic attack after hyperventilating. Patients who panicked during the test more often had a family history of mental disorder, were older at the disorder onset and more often had a history of depressive episodes. The spontaneous and induced panic attacks were very similar in the subjects that exhibited a panic attack. However, in those that did not develop panic after hyperventilating, the spontaneous panic attacks were more often accompanied by chills/hot flushes and much less often accompanied by respiratory symptoms such as shortness of breath, choking sensation, chest pain/discomfort, paresthesia and fear of dying. In another study, involving a one-week self monitoring period, the hyperventilationinduced panic attack group subjects reported greater frequency and severity of respiratory symptoms, meeting the criteria for the respiratory panic disorder subtype ${ }^{(9)}$.

Although these data seem to support a causal role for hyperventilation, there is some evidence against it, and a growing number of studies question the ability of acute hyperventilation to induce panic attacks. Such studies suggest that, although hyperventilation can induce a certain degree of anxiety, it cannot induce a reaction similar to spontaneous panic attacks in panic disorder patients. ${ }^{(34)}$ It is, however, unquestionable that some panic disorder patients present symptoms related to hyperventilation, as also suggested by the evidence of a relationship between the severity of hyperventilation-induced anxiety symptoms and a gradual decrease in cerebral blood flow in response to hypocapnia-induced alveolar hyperventilation. ${ }^{(3)}$ Finally, many studies have shown that hypercapnia definitely has a stronger panicogenic effect than does hyperventilation, although there is as yet no consensus.

\section{Breath-holding}

The breath-holding challenge test, which is a simple method of increasing endogenous $\mathrm{CO}_{2}$, increases $\mathrm{PaCO}_{2}$ and decreases $\mathrm{PaO}_{2}$, resulting in chemoreceptor stimulation and a strong drive to resume breathing. ${ }^{(34)}$ Van der Does ${ }^{(35)}$ developed a breath-holding test that consists of four trials. Each of the first three trials has a 1-min anticipation period, followed by cessation of breathing at functional residual capacity, and a 2-min recovery period. In these instances, the subjects are instructed to stop breathing, then exhale normally (i.e., unforced exhalation), and remain in apnea for as long as possible. The fourth trial consists of breath-holding after inhalation up to vital capacity. A stopwatch is used to measure the breath-holding time. The level of anxiety before and after the test is evaluated, as are panic disorder symptoms.

According to the Klein hypothesis, ${ }^{(5)}$ panic disorder patients are more sensitive to a rise in $\mathrm{CO}_{2}$ and should not be able to hold their breath for long. The breath-holding time has been found to be shorter, ${ }^{(36)}$ and the end-tidal $\mathrm{PaCO}_{2}$ to be lower, in panic disorder patients than in normal controls, demonstrating the lower tolerance to $\mathrm{CO}_{2}$ in the former group. ${ }^{(37)}$ Increased anxiety and panic attacks during the breathholding procedure has been described.$^{(8)}$

\section{$\mathrm{CO}_{2}$ challenge}

Among the numerous agents capable of inducing panic attacks in panic disorder patients, $\mathrm{CO}_{2}$ represents one of the most reliable panicogenic agents. ${ }^{(38)}$ One group of authors observed that subjects with panic disorder, in contrast with healthy controls, develop a panic-like reaction within minutes after beginning to breathe a gas mixture containing $5 \% \mathrm{CO}_{2}{ }^{(4)}$ Panic attacks induced by $\mathrm{CO}_{2}$ have been associated with cardiorespiratory activation including increased respiratory rate and blunted tidal volume response, as well as tachycardia and increased blood pressure. ${ }^{(4,6)}$

An alternative method of $\mathrm{CO}_{2}$ challenge involves a single vital capacity inhalation of a gas mixture containing $35 \% \mathrm{CO}_{2}$ and $65 \%$ oxygen. ${ }^{(6)}$ Under these conditions, healthy subjects present with brief but pronounced respiratory stimulation accompanied by neurovegetative symptoms that largely overlap with those reported by panic patients. In panic disorder patients, the same intervention also induces a sharp, transitory rise in anxiety that has been equated with a real life panic attack. ${ }^{(6,39)}$. Administered in a controlled laboratory environment, the single-breath 35\% $\mathrm{CO}_{2}$ challenge is a brief test whose effects dissi- 
pate completely in a matter of seconds. It has been repeatedly demonstrated that the procedure is safe and devoid of unwanted short- or long-term consequences. ${ }^{(40)}$

The effect of $\mathrm{CO}_{2}$ challenge on the activity of the hypothalamic-pituitary-adrenal (HPA) axis has yet to be studied in depth, and the available data are conflicting. It has been shown that inhalation of low concentrations of $\mathrm{CO}_{2}$ (5\% or $7 \%$ ) do not significantly increase cortisol release in panic disorder patients or normal controls, suggesting that this panicogenic agent does not activate the HPA axis. ${ }^{(41)}$ However, there is evidence that inhalation of $35 \% \mathrm{CO}_{2}$ increases cortisol release in normal subjects. ${ }^{(42)}$ Another hypothesis to explain the link between respiration and the HPA axis is that the HPA axis and respiratory control systems are both reactive to contextual cues such as novelty or anticipation of future challenge. ${ }^{(43)}$

\section{Panic disorder with prominent respiratory symptoms: the respiratory subtype}

There is abundant scientific evidence of a distinct respiratory subtype of panic disorder. Symptoms and clinical features of the respiratory panic disorder subtype are described in Chart 2.

One group of authors evaluated 1,108 panic disorder patients and found that a distinct subtype could be defined by the presence of four or five of the following symptoms during a panic attack $^{(9)}$ : fear of dying; chest pain or discomfort; shortness of breath; paresthesia; and a sensation of choking. Patients with three or less of these symptoms were allocated to the non-respiratory subtype group. The patients with prominent respiratory symptoms also presented with specific characteristics, such as a higher number of spontaneous panic attacks, and seemed to respond better to antidepressants, whereas patients in the non-respiratory subtype group presented with more situational panic attacks and seemed to react better to benzodiazepines. ${ }^{(9)}$ Recent studies have confirmed the idea that respiratory symptoms are the best predictors of the subjective state defined as panic disorder based on the criteria established in the Diagnostic and Statistical Manual of Mental Disorders, Fourth Edition. ${ }^{(44)}$
In one study, $15(93.7 \%)$ of 16 respiratory panic disorder subtype patients and 5 (43.4\%) of 11 non-respiratory panic disorder subtype patients had a panic attack during one of two $\mathrm{CO}_{2}$ challenges. ${ }^{(45)}$ In another study, comparing 117 panic disorder patients of the respiratory and non-respiratory subtypes, using the 35\% $\mathrm{CO}_{2}$ challenge test and the hyperventilation test, $80.3 \%$ and $53.0 \%$ of the patients in the respiratory subtype group had a panic attack in response to $\mathrm{CO}_{2}$ challenge and the hyperventilation test, respectively. However, only $11.8 \%$ of the non-respiratory subtype patients had a panic attack during the $\mathrm{CO}_{2}$ challenge, and $33.3 \%$ had a panic attack during the hyperventilation test. ${ }^{(46)}$

These findings provide an innovative perspective on panic disorder treatment, respiration-focused interventions being proposed and tested to treat panic disorder patients. A recent study provided preliminary evidence that raising end-tidal $\mathrm{PaCO}_{2}$ by means of capnographic feedback is therapeutically beneficial for panic disorder patients with moderate to large effect sizes. ${ }^{(47)}$ In addition, breathing training that targets $\mathrm{PaCO}_{2}$ seem to reduce fear of bodily sensations in panic disorder patients. ${ }^{(48)}$

\section{Pharmacologic implications}

The results of some studies have suggested that anti-panic drugs modulate respiratory physiology. Twelve weeks of anti-panic treatment with tricyclic antidepressants, imipramine and clomipramine in particular, have been found to significantly decrease $\mathrm{CO}_{2}$ sensitivity (as expressed by minute ventilation and end-tidal $\mathrm{CO}_{2}$ ) in patients with panic disorder, whereas no significant changes are detected in healthy subjects. ${ }^{(48)}$ Similar results were obtained with clomipramine, ${ }^{(49)}$ as well as with selective serotonin reuptake inhibitors such as fluoxetine, fluvoxamine, sertraline, paroxetine and citalopram. ${ }^{(50-53)}$ High-potency benzodiazepines have repeatedly been shown to decrease panic/anxiety responses to hypercapnic gas mixtures. ${ }^{(54)}$ Monoamine oxidase inhibitors also reduce $\mathrm{CO}_{2}$ reactivity. ${ }^{(55)}$

It is noteworthy that consumption of alcohol diminishes $\mathrm{CO}_{2}$ sensitivity in panic disorder patients, ${ }^{(56)}$ a finding that sheds light on the high rates of alcohol abuse in panic disorder. 
There is evidence that the respiratory and the non-respiratory subtypes respond differently to pharmacological interventions. ${ }^{(9)}$ Patients belonging to the respiratory subtype present better improvement with imipramine, whereas patients belonging to the non-respiratory subtype respond better to the high-potency benzodiazepine alprazolam. ${ }^{(9)}$ In addition, respiratory subtype patients have been shown to respond earlier to treatment with nortriptyline (a second-generation tricyclic antidepressant) than do non-respiratory subtype patients, the former presenting a response after only 8 weeks, although both groups had improved equally after 52 weeks. ${ }^{(57)}$ Similar behavior has been observed for the high-potency benzodiazepine clonazepam. ${ }^{(58)}$

\section{Final considerations}

There is a substantial amount of data demonstrating that respiratory stimulation is a common event in panic disorder patients during a panic attack. Certain respiratory abnormalities, such as enhanced $\mathrm{CO}_{2}$ sensitivity and thoracic respiration have been detected in panic disorder patients. As a result, it seems that there is a fundamental abnormality in the physiological mechanisms that control breathing in panic disorder. Accumulated evidence suggests that respiratory physiology remains normal in panic disorder patients, and that their tendency to hyperventilate and to panic in response to respiratory stimulants such as $\mathrm{CO}_{2}$ represent the triggering of a hypersensitive fear network. However, some recent evidence supports the idea that such patients have subclinical abnormalities in respiration and in other functions related to body homeostasis. Therefore, we should consider the possibility that a brain center more primitive and lower than the limbic system plays a role. The current understanding of the anatomy of the fear network has been gathered from preclinical studies identifying the brain pathways that promote the acquisition and maintenance of conditioned fear. The amygdala and its brain stem projections, together with the hippocampus and the medial prefrontal cortex, operate within this network. Attempts to obtain patient images of this system during panic attacks have been inconclusive. However, the theory that the fear network is operative and hyperactive in panic disorder patients might explain why medication and cognitive-behavioral therapy are both clearly effective. Although it remains unclear whether the abnormal function underlying panic attacks lies in the limbic system, and therefore primarily related to fear, or in the brain stem, and therefore principally related to a primal emotion, it must be borne in mind that there are complex relationships between these two brain areas. Therefore, in broad terms, panic disorder should be viewed as the complex result of multiple interactions between various brain networks. The evidence of abnormalities in several neurochemical systems might simply be an expression of the complex interaction among brain circuits. Consequently, attempts to focus on one isolated component of this complex array as the pathogenetic system of panic disorder are apparently unwarranted.

\section{References}

1. Nardi AE, Freire RC, Zin WA. Panic disorder and control of breathing. Respir Physiol Neurobiol. 2009;167(1):133-43.

2. American Psychiatric Association. Diagnostic and Statistical Manual for Mental Disorders, fourth ed. (DSM-IV). Washington, DC: American Psychiatric Press; 1994.

3. Gorman JM, Kent JM, Sullivan GM, Coplan JD. Neuroanatomical hypothesis of panic disorder, revised. Am J Psychiatry. 2000;157(4):493-505.

4. Gorman JM, Papp LA, Coplan JD, Martinez JM, Lennon $\mathrm{S}$, Goetz RR, et al. Anxiogenic effects of $\mathrm{CO} 2$ and hyperventilation in patients with panic disorder. Am J Psychiatry. 1994;151(4):547-53.

5. Klein DF. False suffocation alarms, spontaneous panics, and related conditions. An integrative hypothesis. Arch Gen Psychiatry. 1993;50(4):306-17.

6. Griez EJ, Lousberg H, van den Hout MA, van der Molen GM. CO2 vulnerability in panic disorder. Psychiatry Res. 1987;20(2):87-95.

7. Nardi AE, Lopes FL, Valença AM, Nascimento I, Mezzasalma MA, Zin WA. Psychopathological description of hyperventilation-induced panic attacks: a comparison with spontaneous panic attacks. Psychopathology. 2004;37(1):29-35.

8. Nardi AE, Nascimento 1, Valença AM, Lopes FL, Mezzasalma MA, Zin WA. Panic disorder in a breathholding challenge test: a simple tool for a better diagnosis. Arq Neuropsiquiatr. 2003;61(3B):718-22.

9. Briggs AC, Stretch DD, Brandon S. Subtyping of panic disorder by symptom profile. $\mathrm{Br} \mathrm{J}$ Psychiatry. 1993;163:201-9.

10. Gardner WN. The pathophysiology of hyperventilation disorders. Chest. 1996;109(2):516-34.

11. Nardi AE, Valença AM, Nascimento 1, Mezzasalma MA, Lopes FL, Zin WA. Hyperventilation in panic disorder patients and healthy first-degree relatives. Braz J Med Biol Res. 2000;33(11):1317-23.

12. Nardi AE, Valença AM, Nascimento 1, Zin WA. Hyperventilation challenge test in panic disorder 
and depression with panic attacks. Psychiatry Res. 2001;105(1-2):57-65.

13. Papp LA, Martinez JM, Klein DF, Coplan JD, Norman RG, Cole R, et al. Respiratory psychophysiology of panic disorder: three respiratory challenges in 98 subjects. Am J Psychiatry. 1997;154(11):1557-65.

14. Carvalho NS, Ribeiro PR, Ribeiro M, Nunes Mdo P, Cukier A, Stelmach R. Comparing asthma and chronic obstructive pulmonary disease in terms of symptoms of anxiety and depression. J Bras Pneumol. 2007;33(1):1-6.

15. Valença AM, Falcão R, Freire RC, Nascimento 1, Nascentes $\mathrm{R}$, Zin WA, et al. The relationship between the severity of asthma and comorbidities with anxiety and depressive disorders. Rev Bras Psiquiatr. 2006;28(3):206-8.

16. Ritz T, Rosenfield D, Meuret AE, Bobb C, Steptoe A. Hyperventilation symptoms are linked to a lower perceived health in asthma patients. Ann Behav Med. 2008;35(1):97-104.

17. Deshmukh VM, Toelle BG, Usherwood T, O’Grady B, Jenkins CR. Anxiety, panic and adult asthma: a cognitive-behavioral perspective. Respir Med. 2007;101(2):194-202.

18. Niccolai V, van Duinen MA, Griez EJ. Objective and subjective measures in recovery from a $35 \%$ carbon dioxide challenge. Can J Psychiatry. 2008;53(11):737-44.

19. Cavallini MC, Perna G, Caldirola D, Bellodi L. A segregation study of panic disorder in families of panic patients responsive to the 35\% CO2 challenge. Biol Psychiatry. 1999;46(6):815-20.

20. Perna G, leva A, Caldirola D, Bertani A, Bellodi L. Respiration in children at risk for panic disorder. Arch Gen Psychiatry. 2002;59(2):185-6.

21. Horwath E, Adams P, Wickramaratne P, Pine D, Weissman MM. Panic disorder with smothering symptoms: evidence for increased risk in first-degree relatives. Depress Anxiety. 1997;6(4):147-53.

22. Bellodi L, Perna G, Caldirola D, Arancio C, Bertani A, Di Bella D. C02-induced panic attacks: a twin study. Am J Psychiatry. 1998;155(9):1184-8.

23. Suhara T, Sudo Y, Yoshida K, Okubo Y, Fukuda H, Obata $\mathrm{T}$, et al. Lung as reservoir for antidepressants in pharmacokinetic drug interactions. Lancet. 1998;351(9099):332-5.

24. Veasey SC, Panckeri KA, Hoffman EA, Pack Al, Hendricks JC. The effects of serotonin antagonists in an animal model of sleep-disordered breathing. Am J Respir Crit Care Med. 1996;153(2):776-86.

25. Smoller JW, Pollack MH, Systrom D, Kradin RL. Sertraline effects on dyspnea in patients with obstructive airways disease. Psychosomatics. 1998;39(1):24-9.

26. Kraiczi H, Hedner J, Dahlöf P, Ejnell H, Carlson J. Effect of serotonin uptake inhibition on breathing during sleep and daytime symptoms in obstructive sleep apnea. Sleep. 1999;22(1):61-7.

27. Fleetham JA, Clarke H, Dhingra S, Chernick V, Anthonisen NR. Endogenous opiates and chemical control of breathing in humans. Am Rev Respir Dis. 1980;121(6):1045-9.

28. Akiyama Y, Nishimura M, Kobayashi S, Yoshioka A, Yamamoto M, Miyamoto K, et al. Effects of naloxone on the sensation of dyspnea during acute respiratory stress in normal adults. J Appl Physiol. 1993;74(2):590-5.

29. Mezzasalma MA, Valença AM, Lopes FL, Nascimento 1, Zin WA, Nardi AE. Neuroanatomy of panic disorder [Article in Portuguese]. Rev Bras Psiquiatr. 2004;26(3):202-6.
30. Ferrari MC, Busatto GF, McGuire PK, Crippa JA. Structural magnetic resonance imaging in anxiety disorders: an update of research findings. Rev Bras Psiquiatr. 2008;30(3):251-64.

31. Takeuchi Y, McLean JH, Hopkins DA. Reciprocal connections between the amygdala and parabrachial nuclei: ultrastructural demonstration by degeneration and axonal transport of horseradish peroxidase in the cat. Brain Res. 1982;239(2):583-8.

32. Garssen B, van Veenendaal W, Bloemink R. Agoraphobia and the hyperventilation syndrome. Behav Res Ther. 1983;21(6):643-9.

33. Lindsay S, Saqi S, Bass C. The test-retest reliability of the hyperventilation provocation test. J Psychosom Res. 1991;35(2-3):155-62.

34. Zandbergen J, Strahm M, Pols H, Griez EJ. Breath-holding in panic disorder. Compr Psychiatry. 1992;33(1):47-51.

35. Willem Van der Does AJ. Voluntary breath holding: not a suitable probe of the suffocation alarm in panic disorder. Behav Res Ther. 1997;35(8):779-84.

36. Rassovsky Y, Abrams K, Kushner MG. Suffocation and respiratory responses to carbon dioxide and breath holding challenges in individuals with panic disorder. J Psychosom Res. 2006;60(3):291-8.

37. Nardi AE, Nascimento I, Valença AM, Lopes FL, Zin WA, Mezzasalma MA, et al. A breath-holding challenge in panic disorder patients, their healthy first-degree relatives, and normal controls. Respir Physiol Neurobiol. 2002;133(1-2):43-7.

38. Nardi AE, Valença AM, Lopes FL, de-Melo-Neto VL, Freire RC, Veras AB, et al. Caffeine and 35\% carbon dioxide challenge tests in panic disorder. Hum Psychopharmacol. 2007;22(4):231-40.

39. Argyropoulos SV, Bailey JE, Hood SD, Kendrick AH, Rich AS, Laszlo G, et al. Inhalation of 35\% CO(2) results in activation of the HPA axis in healthy volunteers. Psychoneuroendocrinology. 2002;27(6):715-29.

40. Perna G, Battaglia M, Garberi A, Arancio C, Bertani A, Bellodi L. Carbon dioxide/oxygen challenge test in panic disorder. Psychiatry Res. 1994;52(2):159-71.

41. Sinha SS, Coplan JD, Pine DS, Martinez JA, Klein DF, Gorman JM. Panic induced by carbon dioxide inhalation and lack of hypothalamic-pituitary-adrenal axis activation. Psychiatry Res. 1999;86(2):93-8.

42. Abelson JL, Khan S, Lyubkin M, Giardino N. Respiratory irregularity and stress hormones in panic disorder: exploring potential linkages. Depress Anxiety. 2008;25(10):885-7.

43. Colasanti A, Salamon E, Schruers K, van Diest R, van Duinen M, Griez EJ. Carbon dioxide-induced emotion and respiratory symptoms in healthy volunteers. Neuropsychopharmacology. 2008;33(13):3103-10.

44. Meuret AE, Rosenfield D, Hofmann SG, Suvak MK, Roth WT. Changes in respiration mediate changes in fear of bodily sensations in panic disorder. J Psychiatr Res. 2009;43(6):634-41.

45. Valenca AM, Nardi AE, Nascimento I, Zin WA, Versiani M. Respiratory panic disorder subtype and sensitivity to the carbon dioxide challenge test. Braz J Med Biol Res. 2002;35(7):783-8.

46. Freire RC, Lopes FL, Valença AM, Nascimento I, Veras $A B$, Mezzasalma MA, et al. Panic disorder respiratory subtype: a comparison between responses to hyperventilation and $\mathrm{CO} 2$ challenge tests. Psychiatry Res. 2008;157(1-3):307-10. 
47. Meuret AE, Wilhelm FH, Ritz T, Roth WT. Feedback of end-tidal pCO2 as a therapeutic approach for panic disorder. J Psychiatr Res. 2008;42(7):560-8.

48. Gorman JM, Browne ST, Papp LA, Martinez J, Welkowitz L, Coplan JD, et al. Effect of antipanic treatment on response to carbon dioxide. Biol Psychiatry. 1997;42(11):982-91.

49. Pols H, Lousberg H, Zandbergen J, Griez E. Panic disorder patients show decrease in ventilatory response to $\mathrm{CO} 2$ after clomipramine treatment. Psychiatry Res. 1993;47(3):295-6.

50. Bocola V, Trecco MD, Fabbrini G, Paladini C, Sollecito A, Martucci N. Antipanic effect of fluoxetine measured by CO2 challenge test. Biol Psychiatry. 1998;43(8):612-5.

51. Perna G, Bertani A, Gabriele A, Politi E, Bellodi L. Modification of 35\% carbon dioxide hypersensitivity across one week of treatment with clomipramine and fluvoxamine: a double-blind, randomized, placebo-controlled study. J Clin Psychopharmacol. 1997;17(3):173-8.

52. Bertani A, Perna G, Arancio C, Caldirola D, Bellodi L. Pharmacologic effect of imipramine, paroxetine, and sertraline on 35\% carbon dioxide hypersensitivity in panic patients: a double-blind, random, placebo-controlled study. J Clin Psychopharmacol. 1997;17(2):97-101.

53. Bertani A, Caldirola D, Bussi R, Bellodi L, Perna G. The 35\% CO2 hyperreactivity and clinical symptomatology in patients with panic disorder after 1 week of treatment with citalopram: an open study. J Clin Psychopharmacol. 2001;21(3):262-7.

54. Nardi AE, Valença AM, Nascimento 1, Mezzasalma MA, Zin WA. Double-blind acute clonazepam vs. placebo in carbon dioxide-induced panic attacks. Psychiatry Res. 2000;94(2):179-84.

55. Perna G, Cocchi S, Bertani A, Arancio C, Bellodi L. Pharmacologic effect of toloxatone on reactivity to the 35\% carbon dioxide challenge: a single-blind, random, placebo-controlled study. J Clin Psychopharmacol. 1994;14(6):414-8.

56. Kushner MG, Mackenzie TB, Fiszdon J, Valentiner DP, Foa E, Anderson N, et al. The effects of alcohol consumption on laboratory-induced panic and state anxiety. Arch Gen Psychiatry. 1996;53(3):264-70.

57. Nardi AE, Nascimento I, Valença AM, Lopes FL, Mezzasalma MA, Zin WA, et al. Respiratory panic disorder subtype: acute and long-term response to nortriptyline, a noradrenergic tricyclic antidepressant. Psychiatry Res. 2003;120(3):283-93.

58. Nardi AE, Valença AM, Nascimento 1, Lopes FL, Mezzasalma MA, Freire RC, et al. A three-year follow-up study of patients with the respiratory subtype of panic disorder after treatment with clonazepam. Psychiatry Res. 2005;137(1-2):61-70.

\section{About the authors}

\section{Aline Sardinha}

Clinical Psychologist. Laboratory of Panic and Respiration at the Instituto de Psiquiatria da Universidade Federal do Rio de Janeiro (IPUB/UFRJ, Institute of Psychiatry of the Federal University of Rio de Janeiro), Rio de Janeiro, Brazil.

\section{Rafael Christophe da Rocha Freire}

Physician. Laboratory of Panic and Respiration at the Instituto de Psiquiatria da Universidade Federal do Rio de Janeiro (IPUB/UFRJ, Institute of Psychiatry of the Federal University of Rio de Janeiro), Rio de Janeiro, Brazil.

\section{Walter Araújo Zin}

Researcher. Laboratory of Respiration Physiology at the Carlos Chagas Filho Institute of Biophysics, Universidade Federal do Rio de Janeiro (UFRJ, Federal University of Rio de Janeiro), Rio de Janeiro, Brazil

\section{Antonio Egidio Nardi}

Associate Professor. Instituto de Psiquiatria da Universidade Federal do Rio de Janeiro (IPUB/UFRJ, Institute of Psychiatry of the Federal University of Rio de Janeiro), Rio de Janeiro, Brazil. 